\title{
Experimental Study of a Metallic Pressure Cooker Insulated with Kapok Wool
}

\section{Drissa Ouedraogo ${ }^{1^{*}}$, Serge Wendsida Igo², Abdoulaye Compaore ${ }^{2}$, Gaël Lassina Sawadogo, Belkacem Zeghmati ${ }^{3}$, Xavier Chesneau ${ }^{3}$}

${ }^{1}$ Laboratoire d'Energies Thermiques Renouvelables (LETRE), Université Joseph KI-ZERBO, Ouagadougou, Burkina Faso ${ }^{2}$ Département Energie, Institut de Recherche en Sciences Appliquées et Technologies (IRSAT/CNRST), Ouagadougou, Burkina Faso ${ }^{3}$ Laboratoire de Mathématiques et Physique (LAMPS), Université de Perpignan Via Domitia, Perpignan, France Email: *ouedraogodri2016@gmail.com

How to cite this paper: Ouedraogo, D., Igo, S.W., Compaore, A., Sawadogo, G.L., Zeghmati, B. and Chesneau, X. (2020) Experimental Study of a Metallic Pressure Cooker Insulated with Kapok Wool. Energy and Power Engineering, 12, 73-87. https://doi.org/10.4236/epe.2020.122006

Received: December 30, 2019 Accepted: February 24, 2020 Published: February 27, 2020

Copyright $\odot 2020$ by author(s) and Scientific Research Publishing Inc. This work is licensed under the Creative Commons Attribution International License (CC BY 4.0).

http://creativecommons.org/licenses/by/4.0/

\begin{abstract}
This work is devoted to an experimental study of metallic pressure cooker insulated with kapok wool, a vegetal biodegradable fiber. Experiments conducted on the cooling of hot water in the equipment revealed very low heat losses and a time constant of 60 hours on average. As a result, the equipment makes it possible to finish cooking meals only thanks to the heat stored at the beginning of cooking and keeps cooked dishes warm for long hours. The thermal phase shift of the pressure cooker is around $7 \mathrm{~h}$. Cooking tests conducted on some local dishes revealed about $70 \%$ butane gas savings for cooking cowpea and white rice, $38 \%$ for cooking fatty rice, $75 \%$ for pasta and couscous, and $30 \%$ for cooking potato stew. These results show that this technology can contribute to minimizing energy consumption in the restaurant sector.
\end{abstract}

\section{Keywords}

Pressure Cooker, Kapok Wool, Time Constant, Energy Saving, Restaurant Sector

\section{Introduction}

The biomass (firewood, charcoal, animal excrement, organic matter, agricultural or agro-industrial residues, etc.) occupies on average more than $70 \%$ of the energy balances of African countries [1]. Indeed, it accounts for nearly $85 \%$ of the energy balance in developing countries [2] and more than $90 \%$ of households use it as the main energy source in the Sahelians countries [3]. This form of energy is becoming rarer and rarer [4]. 
A study conducted by Boukary OUEDRAOGO has shown that the restaurant sector represents the second largest consumer of energy (wood, coal, etc.) in Burkina Faso [5]. In the world, more than 2.7 billion people use solid biofuels for cooking and heating [6] [7]. The global impacts of the use of this energy (biomass) on the environment are significant. It has been estimated that indoor air pollution due to the use of solid fuels accounts for nearly 4 million deaths by year and accounts for about $4 \%$ of the disease burden in developing countries [8]. The inaccessibility to improved cooking solutions, in addition to causing environmental problems such as deforestation and its corollaries, creates serious problems such as women's increased time and workload and the deterioration of their workload and health. As a result, the fight against desertification and its impact on the climate forces us to rethink our energy system and reinvent our ways of producing and consuming energy. There are energy saving solutions for the catering sector like Norwegian cooking pot. It is advantageously used in the finishing food cooking started on a conventional wood, charcoal or gas-fireplace. As the cooking is not done entirely on the conventional fireplace, it results in a saving of energy (wood, coal, gas, etc.) corresponding to the energy not consumed if the cooking should continue normally on a conventional fireplace.

Since their invention, Norwegian cooking pot has undergone a number of improvements. For example, there is the introduction of electrical regulation of food temperature. Indeed, patent No. PCT/IB2018/055811 describes a smart pressure cooker which is characterized by its ability to stabilize and regulate the temperature of food. In fact, it keeps the already cooked food warm and starts to heat it if a certain programmed time has elapsed or if a threshold temperature is reached [9]. The disadvantage of these improved systems is related to their electrical energy consumption and the use of chemical insulators that can cause environmental problems.

However, vegetable fibers, which are biodegradable have shown their efficiency in the insulation of utilities. It is also known from the patent OAPI No. 185818 of 04.12 .2018 a portable pressure cooker bag which is characterized by an insulation made of crushed raffia and a fabric coating. The author indicates that the bag time constant is about 36 hours [10].

In order to reduce energy consumption in restaurant sector in Burkina Faso and to promote local materials, we have developed a metal pressure cooker insulated with kapok wool, which works without external energy supply.

Experimental studies carried out by Wereme et al. [11] on kapok wool, show very interesting thermo-physical properties of this material. Indeed, they showed that its thermal conductivity varied between 0.03 and $0.04 \mathrm{~W} / \mathrm{m}$. K for a density between 5 and $40 \mathrm{~kg} / \mathrm{m}^{3}$ and average thermal diffusivity of $17.1 \times 10^{-7} \mathrm{~m}^{2} / \mathrm{s}$ [12].

In the same study, they compared the storage life of ice in a pan insulated with kapok wool and in the shell of a commercial refrigerator insulated with polyurethane. Their results show that both equipments have substantially the same storage life. 
Faming Wang [13] analyzed experimentally the heat transfer in kapok wool using a sensor (HIH-3610). It appears that the use of kapok as a thermal insulating material in the fabric makes it possible to minimize the heat losses of the human body. Moreover, the influence of temperature and wind speed on heat transfer through kapok was analyzed and compared to that of cotton. It has been shown that with kapok, the heat losses of the human body are lower than those obtained by cotton.

As seen, kapok wool, which is a vegetal insulator, can be well used in the manufacture of utilities. In addition, this material is available locally and its exploitation can create new economic sectors.

Therefore, the objective of this work is to conduct an experimental study on a prototype of pressure cooker insulated with kapok wool. The study will focus in particular on the determination of the level of heat losses $(U)$, the time constant $(\tau)$ as well as the energy savings achieved by the equipment during the cooking of certain local dishes.

\section{Materials and Methods}

\subsection{Materials}

We have for this study:

\subsubsection{Metal Pressure Cooker}

The pressure cooker has a parallelepiped shape $(L \times w \times H)=65 \mathrm{~cm} \times 60 \mathrm{~cm} \times$ $50 \mathrm{~cm}$ ) box made of $2 \mathrm{~mm}$ thick steel sheet (1) which encloses the insulation system consisting of $15 \mathrm{~cm}$ thick kapok wool (4). The kapok wool of density 50 $\mathrm{kg} / \mathrm{m}^{3}$ is protected from the outer wall by a $15 \mathrm{~mm}$ thick wooden sheet. The box is equipped with two metal arms (2) fixed on both sides, used to lift it. It also has a $2 \mathrm{~mm}$ thick steel closure consisting of a metal cover (3) on which is fixed a wooden sheet $15 \mathrm{~mm}$ thick (5). A cushion padded with $15 \mathrm{~cm}$ thick kapok wool and sewn in a black peach skin fabric (7) is used to seal the pressure cooker. The device is equipped with a mobile steel support (8) equipped with 4 wheels to facilitate its mobility. Figure 1 shows the technical diagram of the pressure cooker.

Figure 2 shows the prototype of metal the pressure cooker.

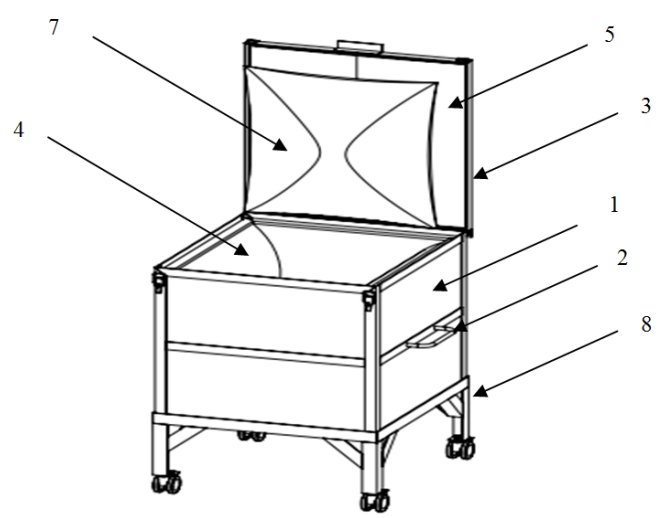

Figure 1. Technical diagram of the pressure cooker. 


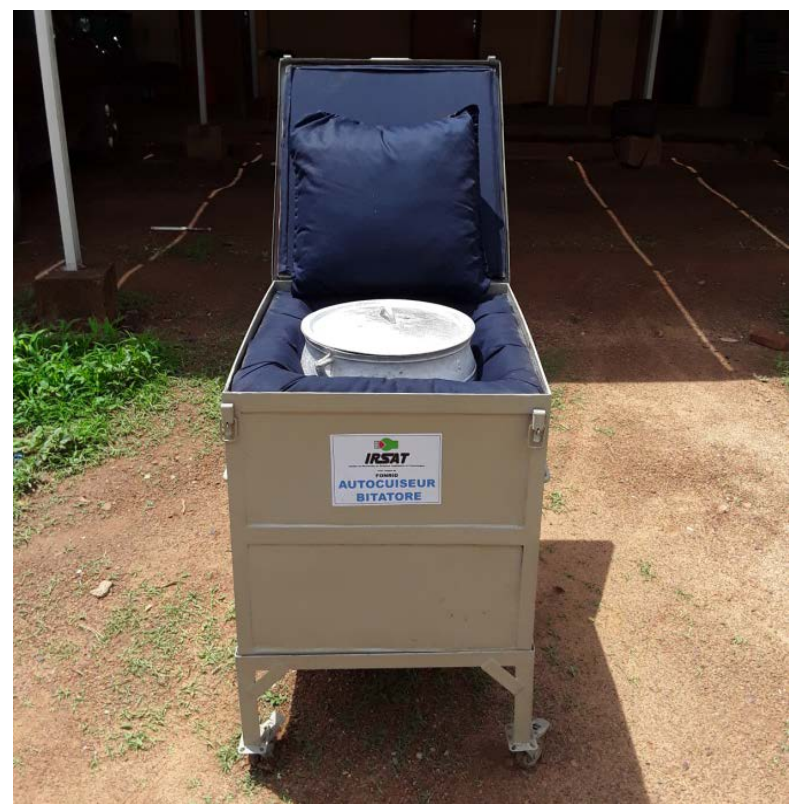

Figure 2. Prototype of metal pressure cooker, source: IRSAT.

\subsubsection{Other Cooking Equipment}

A gas fireplace with a $6 \mathrm{~kg}$ gas cylinder and a 22 liter pot were used to heat the water. Two gas fireplaces with two $12 \mathrm{~kg}$ gas cylinders and two 22 liter pots were used for food preparation.

\subsubsection{Measuring Equipments}

The instrumentation chain consists of nine (09) K-type thermocouples of uncertainty $\pm 1.5^{\circ} \mathrm{C}$, connected to a LOGGER GL840 midi data logger with a tolerance of: $0.05 \%$ (read value) $\pm 1^{\circ} \mathrm{C}$ and a $1 \mathrm{~g}$ precision kitchen scale used to weigh the different food products.

The thermocouples are distributed as follows:

- One (01) thermocouple is placed in the cooking pot to monitor the temperature of the hot water $\left(T_{\text {int }}\right)$;

- Six (06) thermocouples are placed on the six outer faces of the pressure cooker, allowing the temperature of the outer walls $\left(T_{\text {ext }}\right)$ to be monitored;

- Two (02) thermocouples make it possible to follow the evolution of the ambient temperature.

\subsection{Methods}

\subsubsection{Determination of Heat Losses Levels and the Time Constant of the Pressure Cooker}

A pot of capacity 22 liters filled with water is heated at $90^{\circ} \mathrm{C}, 80^{\circ} \mathrm{C}, 70^{\circ} \mathrm{C}$ to prevent mass losses and is introduced into the pressure cooker. The equipment is immediately sealed. The evolution of the temperature of the hot water, as well as the temperatures of the walls of the equipment and the ambient medium is monitored for three (03) days. Figure 3 shows the experimental device for the determination of heat losses and time constant. 


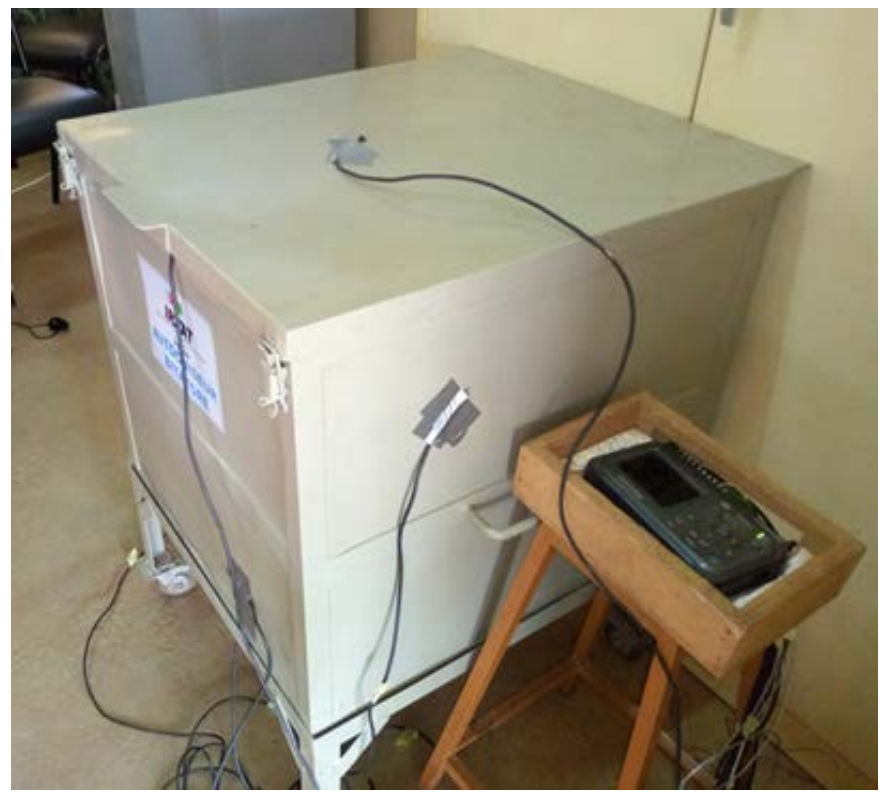

Figure 3. Experimental device for the determination of heat losses and time constant.

1) Experimental protocol for the calculation of heat losses

If a steady state regime is assumed during the operation of the pressure cooker, and a uniform temperature distribution, the energy balance equation can be written as follows [14]:

$$
E_{i}-U A\left(T_{i n t}-T_{\text {ext }}\right) \Delta t=E_{f}
$$

where:

$$
\Delta E=E_{i}-E_{f}=U A\left(T_{\text {int }}-T_{\text {ext }}\right) \Delta t
$$

The thermal losses are:

$$
U=\frac{\Delta E}{A\left(T_{\text {int }}-T_{\text {ext }}\right) \Delta t}
$$

As seen, the determination of $U$ involves calculating $\Delta E$ which can easily determined for the case of simple systems such as water:

$$
\Delta E=m_{e} C p\left(T_{\text {fin }}-T_{\text {int }}\right)
$$

The calculations of $\Delta E$ and $U$ will be tainted with uncertainties:

$$
\begin{gathered}
\Delta(\Delta E)=\left(\frac{\Delta m_{e}}{m_{e}}+\frac{\Delta T_{\text {fin }}}{T_{\text {fin }}}+\frac{\Delta T_{\text {int }}}{T_{\text {int }}}\right) \Delta E \\
\Delta U=\left(\frac{\Delta(\Delta E)}{\Delta E}+\frac{\Delta T_{\text {int }}}{T_{\text {int }}}+\frac{\Delta T_{\text {ext }}}{T_{\text {ext }}}+\frac{\Delta(\Delta t)}{\Delta t}+\frac{\Delta A}{A}\right) U
\end{gathered}
$$

The value of the pressure cooker area is given by the following relation:

$$
A=2 \times H(L+w)+2 \times L \times w
$$

The uncertainty of $A$ is: 


$$
\frac{\Delta A}{A}=2 \times\left(\frac{\Delta H}{H}+\frac{\Delta L}{L}+\frac{\Delta w}{w}\right)
$$

2) Experimental protocol for calculating the time constant

The time constant defines the time for which the temperature amplitude (difference between the initial temperature and the final temperature) is divided by e $(e=2.7)[15]$. We assume that at the infinite moment, a thermal equilibrium is established between the equipment and the external environment. So:

$$
\begin{gathered}
t=0, T \rightarrow T_{0} \\
t=\tau, T \rightarrow\left(T_{0}-T_{\infty}\right) / \mathrm{e} \\
t \rightarrow \infty, T \rightarrow T_{\infty}
\end{gathered}
$$

By analogy with electricity, we can admit an exponential evolution of the function $\left(T_{0}-T_{\infty}\right) /\left(T-T_{\infty}\right)$ :

$$
\begin{gathered}
\frac{T_{0}-T_{\infty}}{T-T_{\infty}}=\mathrm{e}^{\frac{U A}{C} t} \\
\frac{1}{\tau}=\frac{U A}{c}=\succ \frac{T_{0}-T_{\infty}}{T-T_{\infty}}=\mathrm{e}^{\frac{t}{\tau}}
\end{gathered}
$$

If we apply the natural logarithm to the previous relation, we obtain:

$$
\ln \left(\frac{T_{0}-T_{\infty}}{T-T_{\infty}}\right)=\frac{t}{\tau}
$$

Determining the slope of the straight-line $y=f(t)$ then makes it possible to determine the time constant of the pressure cooker.

\subsubsection{Determination of Energy Savings}

For the determination of energy savings, we chose six local dishes usually consumed namely: white rice, fatty rice, cowpea, potato stew, pasta and couscous. The experimental protocol follows the following steps:

1) For each dish, cook normally on the conventional fireplace and measure the butane gas consumption $\left(M_{1}\right)$. Cowpea is soaked in cold water for one hour before cooking.

2) Repeat the experiment for each dish in the same proportions (same mass of products and same quantities of ingredients), but here the cooking stops when the meal acquires enough thermal inertia, usually when the boiling is reached. Note the butane gas consumption of this precooking phase $\left(M_{2}\right)$.

3) Immediately transfer the meal in the pressure cooker and close it tightly to finish cooking.

The energy saving $(E E)$ is given in percentage by the relation (12):

$$
E E=\left(\left(M_{1}-M_{2}\right) / M_{1}\right) \times 100
$$

The uncertainty of $E E$ is determined by the expression

$$
\Delta E E=\left(\frac{\Delta M_{1}+\Delta M_{2}}{M_{1}-M_{2}}+\frac{\Delta M_{1}}{M_{1}}\right) E E
$$




\section{Results and Discussions}

\subsection{Analysis of Temperature Curves}

\subsubsection{Variation of the Temperature of the Hot Water inside the Pot}

Figures 4-6 respectively show the evolution of the temperature of hot water as well as that of the walls of the pressure cooker and the ambient environment. The initial temperature inside the pressure cooker is $90^{\circ} \mathrm{C}$ in Figure $4,80^{\circ} \mathrm{C}$ in Figure 5 and $70^{\circ} \mathrm{C}$ in Figure 6. These experiments were repeated several times and the results are almost similar.

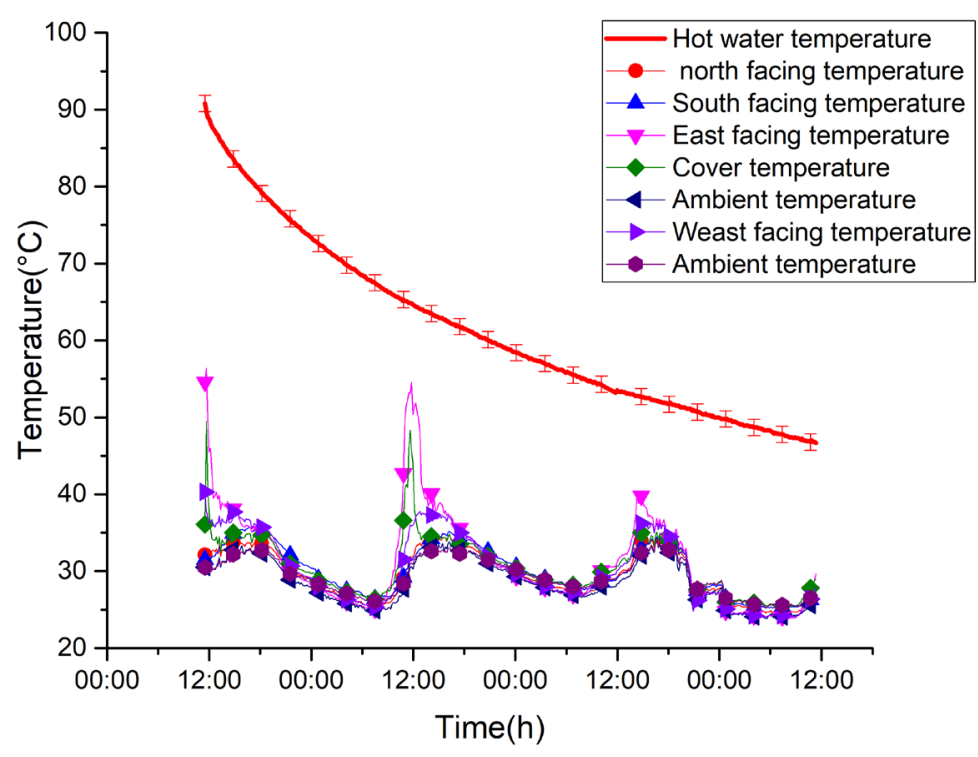

Figure 4. Time dependant temperatures evolution for an initial temperature of hot water at $90^{\circ} \mathrm{C}$.

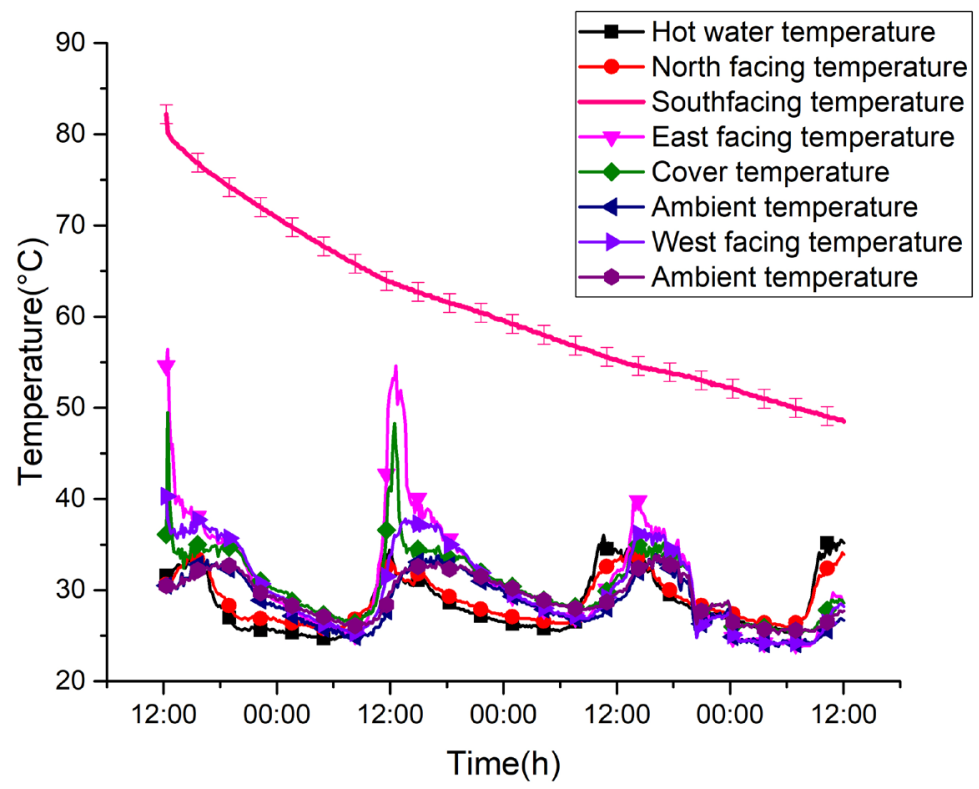

Figure 5. Time dependant temperatures evolution for an initial temperature of hot water at $80^{\circ} \mathrm{C}$. 


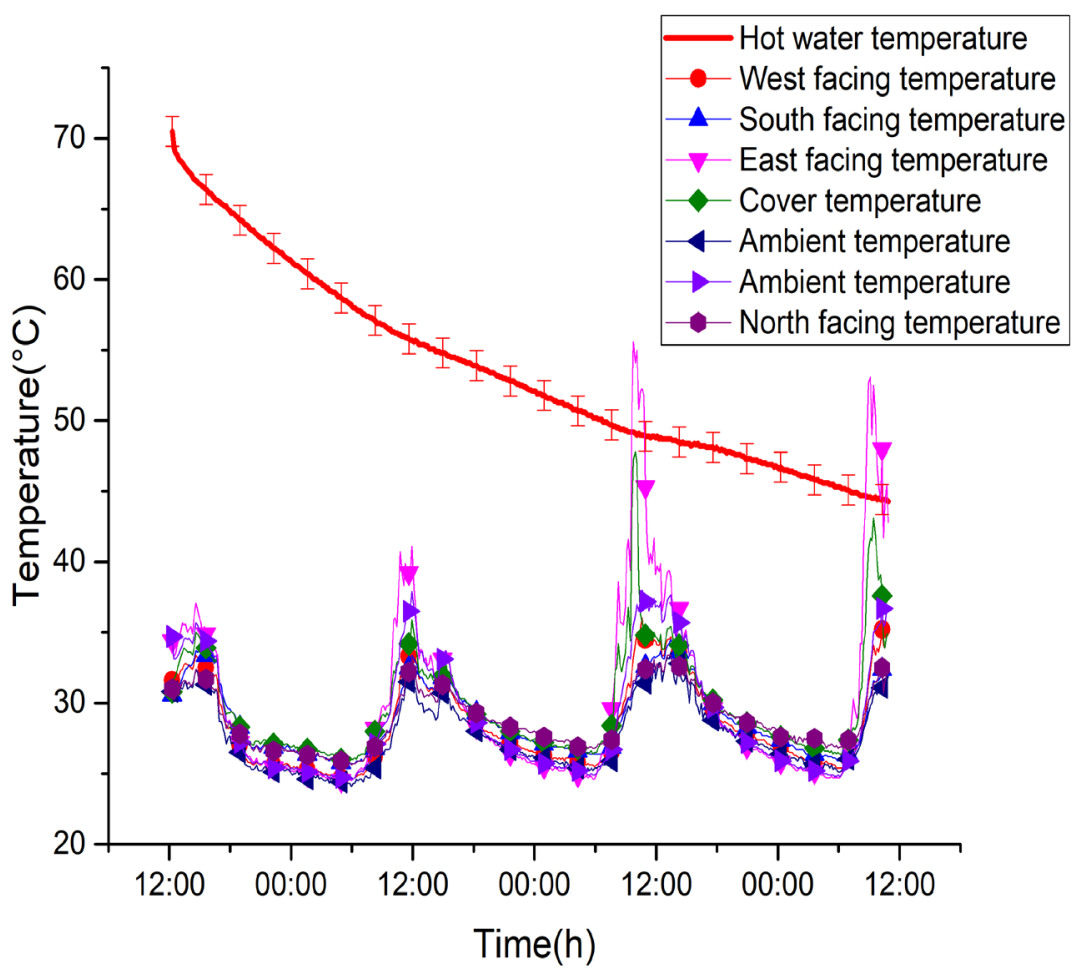

Figure 6. Time dependant temperatures evolution for an initial temperature of hot water at $70^{\circ} \mathrm{C}$.

We observe that the internal temperature decreases over time in a homogeneous way throughout the experiment whatever the initial temperature inside the pot. This decrease is greater at the beginning of the experiment (because of the strong temperature gradients) and then stabilizes gradually as the insulation shields heat transfers to the outside. It is also noted that despite the wide variation in temperatures (around $50^{\circ} \mathrm{C}$ ) of the wall of the pressure cooker, they do not affect the internal temperature of the kettle placed inside the pressure cooker. This shows the good insulation of our pressure cooker. The temperatures of the walls follow those of the ambient temperature. The temperature peaks observed correspond to the solar noon, where the sunshine is maximum. The high temperatures at the level of the East face are explained by the fact that this face is subjected to direct sunshine.

\subsubsection{Variation of the Internal Vacuum Temperature of the Pressure Cooker}

We represent in Figure 7, the evolution of the pressure cooker internal vacuum temperature and external temperatures in order to determine the thermal phase shift.

Considering the internal and external temperature peaks, we note that the thermal phase shift of the equipment is about $7 \mathrm{~h}$ for a kapok wool density 50 $\mathrm{kg} / \mathrm{m}^{3}$ and thickness $15 \mathrm{~cm}$, which is relatively important for this material which is an ecological insulator. 


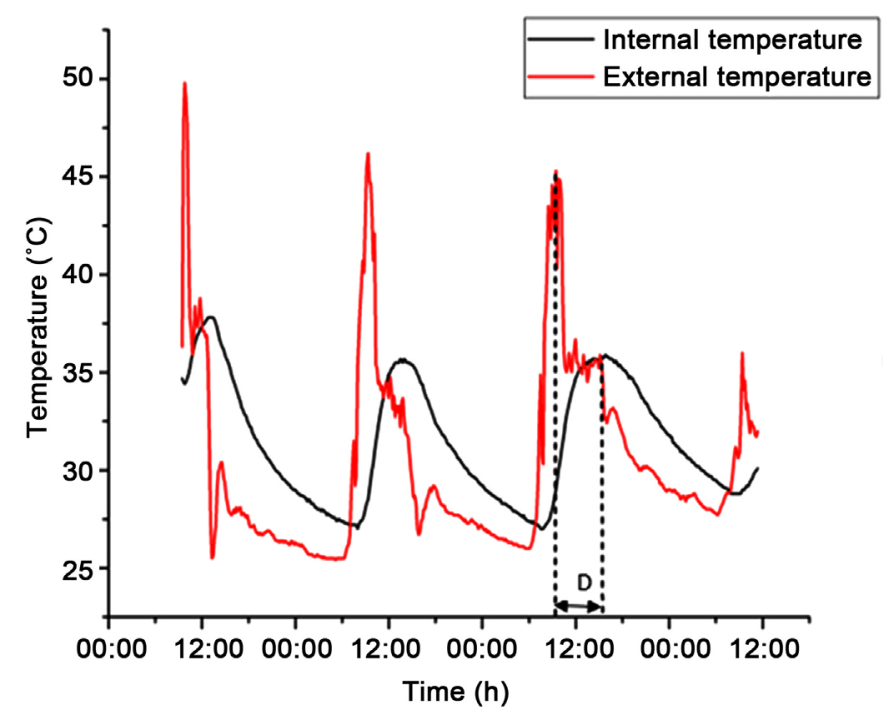

Figure 7. Evolution of the internal and external temperatures of the pressure cooker.

\subsection{Thermal Losses and Time Constant}

\subsubsection{Thermal Losses Analysis}

From the measured temperatures, we determined the values of thermal losses as a function of time intervals. The value of $U$ is related to the amount of heat described by Equation (13). The following table gives the values of thermal losses as a function of time intervals. Table 1 shows the values of thermal losses as a function of time intervals.

Table 1. Values of thermal losses as a function of time intervals.

\begin{tabular}{|c|c|c|c|c|c|c|c|c|c|}
\hline Time & $T_{\text {int }}$ & $T_{e x t}$ & $\overline{T_{i t t}}$ & $\overline{T_{\text {ext }}}$ & $\overline{T_{i n t}}-\overline{T_{\text {ext }}}$ & $T_{f i n}-T_{i n i}$ & $\Delta t$ & $\Delta E$ & $U$ \\
\hline $\begin{array}{l}13: 21: 34 \\
22: 35: 42\end{array}$ & $\begin{array}{l}90.3 \\
75.3\end{array}$ & $\begin{array}{c}27 \\
30.1\end{array}$ & 81.9 & 30.8 & 51.1 & 18 & 33,600 & $1,640,520$ & $0.47 \pm 0.03$ \\
\hline $\begin{array}{l}22: 45: 42 \\
09: 45: 42\end{array}$ & $\begin{array}{l}75.2 \\
65.6\end{array}$ & $\begin{array}{l}29.3 \\
28.9\end{array}$ & 70.02 & 27.8 & 42.22 & 9.6 & 39,600 & 874,944 & $0.24 \pm 0.01$ \\
\hline $\begin{array}{l}09: 55: 42 \\
17: 15: 42\end{array}$ & $\begin{array}{l}65.4 \\
61.6\end{array}$ & $\begin{array}{c}29 \\
27.5\end{array}$ & 63.4 & 30.3 & 33.1 & 3.8 & 26,400 & 346,332 & $0.19 \pm 0.01$ \\
\hline $\begin{array}{l}17: 35: 42 \\
10: 23: 14\end{array}$ & $\begin{array}{l}61.5 \\
53.5\end{array}$ & $\begin{array}{l}27.7 \\
26.8\end{array}$ & 56.3 & 24.1 & 32.2 & 8 & 60,600 & 728,120 & $0.15 \pm 0.01$ \\
\hline $\begin{array}{l}10: 33: 14 \\
13: 38: 54\end{array}$ & $\begin{array}{l}53.6 \\
46.4\end{array}$ & $\begin{array}{l}26.9 \\
31.5\end{array}$ & 52.1 & 28.5 & 23.6 & 2.7 & 34,800 & 246,078 & $0.14 \pm 0.01$ \\
\hline
\end{tabular}

The first calculated value of $U\left(0.47 \mathrm{~W} / \mathrm{m}^{2} \cdot{ }^{\circ} \mathrm{C}\right)$ is the largest during the experiment. This is explained by the fact that as soon as the hot water is introduced into the pressure cooker, the temperature gradient inside the pressure cooker increases sharply. It is the appearance of this strong temperature gradient which explains the level of heat loss quite important at the beginning. Thereafter, the 
temperature of the kapok wool gradually increases and the temperature gradient decreases resulting in low values of $U$ until thermal equilibrium with the environment.

\subsubsection{Analysis of the Time Constant of the Pressure Cooker}

The time constant is a parameter that characterizes the rapidity of the loss of heat. The determination of the slope of the line $y=f(t)$ permits to determine the time constant of the pressure cooker. Figure 8 shows $\ln \left(T_{0}-T_{\infty}\right) /\left(T-T_{\infty}\right)$ as a function of time for the 1 st experiment.

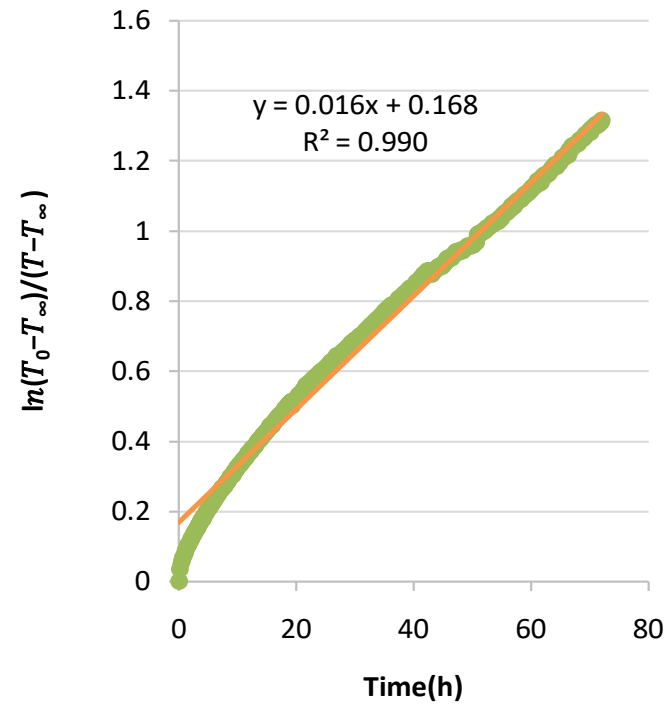

Figure 8. $\ln \left(T_{0}-T_{\infty}\right) /\left(T-T_{\infty}\right)$ as a function of time (1st experiment).

The line equation is:

$$
y=0.0162 x+0.1687
$$

let, $1 / \tau=0.0162$ and $\tau=61.72$ hours.

Two other experiments were made and two other line equations:

Line equation of the second experiment:

$$
\begin{aligned}
& y=0.0169 x+0.1892 \\
& R^{2}=0.987
\end{aligned}
$$

let, $1 / \tau=0.0169$ and $\tau=59.17$ hours.

Line equation of the third experiment:

$$
\begin{aligned}
& y=0.0171 x+0.1555 \\
& R^{2}=0.9943
\end{aligned}
$$

let, $1 / \tau=0.0171$ and $\tau=58.47$ hours. Hence an average of 59.78 hours.

We can retain an average time constant of 60 hours. This result is directly related to the low thermal losses shown above and its meaning is very important for this study. Indeed, it should be understood that it is 60 hours after the introduction of a heated body in the equipment that we can observe a good gap be- 
tween its initial and current temperature.

\subsection{Analysis of Energy Savings in Butane Gas}

The butane gas savings for cooking dishes are summarized in Table 2.

Table 2. Energy savings achieved with the pressure cooker.

\begin{tabular}{|c|c|c|c|c|c|c|}
\hline Dishes & $\begin{array}{l}\text { White } \\
\text { rice }\end{array}$ & Fatty rice & cowpea & potato stew & Pasta & Couscous \\
\hline $\begin{array}{l}\text { mass of food products } \\
(\mathrm{kg}) \text { for each cooking }\end{array}$ & 5 & 5 & 5 & 5.5 & 5 & 5 \\
\hline $\begin{array}{l}\text { Normal cooking } \\
\text { duration with a } \\
\text { conventional fireplace }\end{array}$ & $1 \mathrm{~h} 10$ & $1 \mathrm{~h} 45 \mathrm{mn}$ & $2 \mathrm{~h}$ & $1 \mathrm{~h} 45$ & $1 \mathrm{~h}$ & $45 \mathrm{mn}$ \\
\hline $\begin{array}{l}\text { Precooking duration } \\
\text { with a conventional } \\
\text { fireplace }\end{array}$ & $20 \mathrm{mn}$ & $1 \mathrm{~h}$ & $45 \mathrm{mn}$ & $1 \mathrm{~h} 15 \mathrm{mn}$ & $15 \mathrm{mn}$ & $10 \mathrm{mn}$ \\
\hline $\begin{array}{l}\text { Minimum duration of } \\
\text { cooking in the pressure } \\
\text { cooker }\end{array}$ & $1 \mathrm{~h}$ & $45 \mathrm{mn}$ & $4 \mathrm{~h}$ & $1 \mathrm{~h}$ & $45 \mathrm{mn}$ & $30 \mathrm{mn}$ \\
\hline M1 (kg) & 1 & 1.3 & 1.4 & 1 & 0.9 & 0.6 \\
\hline M2 (kg) & 0.3 & 0.8 & 0.42 & 0.7 & 0.22 & 0.15 \\
\hline Energy saving (\%) & $70 \pm 0.38$ & $38 \pm 0.48$ & $70 \pm 0.27$ & $30 \pm 0.76$ & $75 \pm 0.40$ & $75 \pm 0.61$ \\
\hline
\end{tabular}

The energy saving results obtained are explained by those obtained previously. Indeed, because of low heat losses, the thermal inertia of the meal placed in the pressure cooker varies very little, and cooking continues normally in the pressure cooker without additional energy consumption. Energy savings are more important for meals that require very little cooking time in the precook phase compared to the cooking time of a normal kitchen.

\section{Conclusions}

A metallic pressure cooker insulated with kapok wool of thickness $15 \mathrm{~cm}$ and density $50 \mathrm{~kg} / \mathrm{m}^{3}$ has been experimentally investigated in the present work. The evolution of the hot water-cooling temperature maintained in the equipment coupled with an electrical analogy made it possible to determine the time constant of the pressure cooker. The thermal losses were determined by making an energy balance on the hot water exchanges with the environment. Energy saving of cooking was determined by making energy mass balance between a complete cooking on a gas fireplace and a cooking completed by the pressure cooker. The main results are summarized as follows:

- Thermal losses in the pressure cooker are low, confirming the good insulating properties of kapok wool observed by other authors,

- The pressure cooker keeps the heat for a long time (around 60 hours) and the thermal phase shift of the pressure cooker is around $7 \mathrm{~h}$,

- The pressure cooker saves substantial energy cooking (between 30\% and 75\% 
under the conditions of this study). This last result shows that this technology can efficiently contribute to energy management in the restaurant sector.

\section{Acknowledgements}

The authors express their deep gratitude to the Embassy of France in Burkina Faso, the National Research Fund for Innovation and Development (FONRID) and the International Science Program (ISP) for their financial support.

\section{Conflicts of Interest}

The authors declare no conflicts of interest regarding the publication of this paper.

\section{References}

[1] Institut de l'énergie et de l'environnement de la francophonie (2000) Pour une gestion durable de la biomasse-énergie. Edition: Caractéra Inc.

[2] Compaoré, A. (2018) Etude des performances thermiques d'un habitat type du Burkina Faso. Application: Contribution à la mise en place d'une réglementation thermique. Thèse de doctorat à l'Université Ouaga1 Pr Joseph kI ZERBO.

[3] Magrin, G. (2007) L'Afrique sub-saharienne face aux famines énergétiques. https://doi.org/10.4000/echogeo.1976

[4] Suresh, R., Singh, V.K., Malik, J.K., Datta, A. and Pal, R.C. (2016) Evaluation of the Performance of Improved Biomass Cooking Stoves with Different Solid Biomass Fuel Types. Biomass and Bioenergy, 95, 27-34. https://doi.org/10.1016/j.biombioe.2016.08.002

[5] Ouedraogo, B. (2006) La demande de bois-énergie à Ouagadougou: Esquisse d'évaluation de l'impact physique et des échecs des politiques de prix. Développement durable et territoires, 2004-2010.

[6] International Energy Agency (IAE) (2010 Energy Poverty: How to Make Modern Energy Access Niversal, Paris. World Energy Outlook. https://doi.org/10.4000/developpementdurable.4151

[7] MacCarty, N.A. and Bryden, K.M. (2016) A Generalized Heat-Transfer Model for Shielded-Fire Household Cookstoves. Energy for Sustainable Development, 33, 96-107. https://doi.org/10.1016/j.esd.2016.03.003

[8] Legros, G., Havet, I., Bruce, N. and Bonjour, S. (2009) The Energy Access Situation in Developing Countries.

[9] Mohite, V. and Pal, S.K. (2019) Autocuiseur Intelligent. Brevet No. PCT/IB2018/055811.

[10] Sosso, M.O.T. and Grace, E.P. (2018) Sac Autocuiseur Portatif. Brevet No. OAPI 18518.

[11] Wereme, A., Tamba, S., Saar, M., Diene, A., Diagne, I., Niang, F. and Sissoko, G. (2010) Caractérisation des isolants thermiques locaux de type sciure de bois et kapok: Mesure de coefficient global d'échange thermique et de la conductivité thermique. Journal des Sciences, 10, 39-46.

[12] Voumbo, M.L., Wereme, A., Tamba, S., Gaye, A.S., Adj, I.M. and Sissoko, G. (2008) Caractérisation des propriétés thermophysiques du kapok. Journal des Sciences, 8 , 33-43.

[13] Wang, F.M. (2009) Comparisons of Thermal and Evaporative Resistances of Kapok Coats and Traditional Down Coats. Fibres \& Textiles in Eastern Europe, 18, 88-92. 
[14] Voumbo, M.L., Wereme, A., Tamba, S., Gaye, A.S., Adj, I.M. and Sissoko, G. (2010) Haracterization of the Thermophysical Properties of Kapok. Research Journal of Applied Sciences, Engineering and Technology, 2, 143-148.

[15] Chahwane, L. (2011) Valorisation de l'inertie thermique pour la performance énergétique des bâtiments. Architecture, aménagement de l'espace, thèse de doctorat à l'Université de Grenoble. 


\section{Nomenclature}

$E_{i}$ : Initial energy in the metal (J)

$E_{f}$ Final energy in the metal (J)

$U$ : Overall coefficient of heat loss $\left(\mathrm{W} / \mathrm{m}^{2} \cdot{ }^{\circ} \mathrm{C}\right)$

$T_{\text {int: }}$ Initial water temperature $\left({ }^{\circ} \mathrm{C}\right)$

$T_{\text {ext }}$ Outside temperature of the wall $\left({ }^{\circ} \mathrm{C}\right)$

$\overline{T_{\text {ext }}}$ : Average of $T_{\text {ext }}$ in the time interval $\left({ }^{\circ} \mathrm{C}\right)$

$\overline{T_{\text {int }}}$ : Average of $T_{\text {int }}$ in the time interval $\left({ }^{\circ} \mathrm{C}\right)$

$T_{\text {fin }}$ : Final temperature of the water $\left({ }^{\circ} \mathrm{C}\right)$

$T_{0}$ : Water temperature $\left(90^{\circ} \mathrm{C}\right)$ at the beginning of the experiment

T: Indoor temperature at time $t\left({ }^{\circ} \mathrm{C}\right)$

$T_{\infty}$ : Final temperature at the infinite moment from the beginning of the experiment $\left({ }^{\circ} \mathrm{C}\right)$

$A$ : Surface of the pressure cooker $\left(\mathrm{m}^{2}\right)$

$\Delta$ : The Laplace operator

$\tau$. Time constant (h)

$m_{e}$ : Mass of water $(\mathrm{kg})$

h: Hours

mn: Minute

$D$ : Thermal phase shift (h)

$L$ : Pressure cooker length (m)

$w$ : Pressure cooker width (m)

$H$ : Pressure cooker height (m)

$\Delta m_{e}:$ Absolute uncertainty on the mass of water $(\mathrm{kg})$

$\Delta T_{\text {int: }}$ Absolute uncertainty on $T_{\text {int }}\left({ }^{\circ} \mathrm{C}\right)$

$\Delta T_{\text {fin }}$ : Absolute uncertainty on $T_{\text {fin }}\left({ }^{\circ} \mathrm{C}\right)$

$\Delta T_{\text {exi }}$ Absolute uncertainty on $T_{\text {ext }}\left({ }^{\circ} \mathrm{C}\right)$

$\Delta T_{\text {init: }}$ Absolute uncertainty on $T_{\text {init }}\left({ }^{\circ} \mathrm{C}\right)$

$\Delta(\Delta E)$ : Absolute uncertainty on $\Delta E(\mathrm{~J})$

$\Delta(U)$ : Absolute uncertainty over $U\left(\mathrm{~W} /\left(\mathrm{m}^{2} .{ }^{\circ} \mathrm{C}\right)\right)$

$\triangle A$ : Absolute uncertainty on $A\left(\mathrm{~m}^{2}\right)$

$\Delta T$ : Absolute uncertainty of temperature $\left({ }^{\circ} \mathrm{C}\right)$

$\Delta(\Delta t)$ : Absolute uncertainty of time (s)

$\Delta L$ : Absolute uncertainty on $L$ in meter $(\mathrm{m})$

$\Delta H$ : Absolute uncertainty on $H$ in meter (m)

$\Delta$ : Absolute uncertainty on 1 in meter $(\mathrm{m})$

$t$. Time (s)

$\Delta t$. Time interval considered (s)

s: seconds

$C p$ : specific heat of the material $(\mathrm{J} /(\mathrm{kg} \cdot \mathrm{K}))$

$C$ : Heat capacity of the pressure cooker $\left(\mathrm{Wh} /{ }^{\circ} \mathrm{C}\right)$

Mav1: Mass of the gas cylinder before cooking with the conventional firebox (kg) 
Mav2: Mass of the gas cylinder before cooking with the pressure cooker $(\mathrm{kg})$

Map1: Mass of the gas cylinder at the end of cooking with the conventional firebox $(\mathrm{kg})$

Map2: Mass of the gas cylinder at the end of cooking with the pressure cooker $(\mathrm{kg})$

$M_{1}$ : Quantity of energy consumed with the conventional fireplace $(\mathrm{kg})$

$M_{2}$ : Quantity of energy consumed with the pressure cooker $(\mathrm{kg})$

$E E$ : Energy saving (\%) 